\title{
LA EXISTENCIA DE LA CLÁUSULA ARBITRAL Y LA VOLUNTAD DE LAS PARTES.
}

\section{THE EXISTENCE OF THE ARBITRAL CLAUSE AND THE WILL OF THE PARTIES.}

\author{
Carmen María Noriega Linares \\ Doctoranda en Derecho por la Universidad de Murcia \\ Letrada colegiada ejerciente del Ilustre Colegio de Abogados de Murcia
}

Recibido: 11.11.2020 / Aceptado: 27.11.2020

DOI: https://doi.org/10.20318/cdt.2021.6008

\begin{abstract}
Resumen: El auto objeto del presente comentario estima, en sentido parcial, el auto dictado por el Juzgado de Primera Instancia ${ }^{\circ} 32$ de Barcelona en el que se discute la existencia o no de una sumisión a arbitraje. El auto del Juzgado se pronuncia de forma positiva en relación con la declinatoria presentada por la demandada, en la que alega la existencia de una cláusula arbitral inserta en el contrato de importación suscrito entre la demandante y demandada. Esta cláusula estipula que el contrato se interpretará de conformidad a la legislación eslovena y que el arbitraje tendrá lugar en Ljubljana, República de Eslovenia.

Por su parte, la demandante y recurrente alega que no hubo intención clara de las partes de introducir esa cláusula arbitral y que su colocación en el contrato fue fruto de un error material. Añade que de considerarse una cláusula arbitral ésta debería ser considerada inoperante e ineficaz por sus lagunas e irregularidades insalvables.
\end{abstract}

Palabras clave: arbitraje, cláusula arbitral, requisitos de forma, forma escrita, ley aplicable, validez de la cláusula, voluntad inequívoca, vulneración del art. $24 \mathrm{CE}$.

Abstract: The order object of this comment considers admissible, in a partial sense, the order issued by the Court of First Instance $n^{\circ} 32$ of Barcelona, in which the existence or not of a submission to arbitration is argued. The court order pronounces positively in relation to the jurisdiction plea presented by the defendant, which alleges the existence of an arbitration clause inserted in the import contract signed between the plaintiff and the defendant. This clause stipulates that the contract will be interpreted in accordance with Slovenian Law and the arbitration will take place in Ljubljana, Republic of Slovenia.

For its part, the plaintiff and appellant alleges that there was no clear intention of the parties to introduce this arbitration clause and that its placement in the contract was the result of a material error. It adds that if the arbitration clause is considered as inserted, it should be considered inoperative and ineffective due to its insurmountable gaps and irregularities.

Keywords: arbitration, arbitral clause, formal requirements, written form, applicable law, validity of the clause, unequivocal will, violation of art. 24 Spanish Constitution.

Sumario: I. Antecedentes de hecho y la instancia de origen. II. El análisis de la cláusula arbitral. Lo que tendría que haber sucedido. 1. La forma de la cláusula arbitral: existencia y validez. 2. La voluntad de las partes. III. El caos normativo del que hace gala la AP. Lo que de verdad pasó. 1. La forma de la cláusula arbitral. 2. La voluntad de las partes. IV. Principios constitucionales en el arbitraje: el derecho de defensa. V. Régimen jurídico de la elección de la Ley aplicable al convenio arbitral y de la Ley aplicable a la elección del tribunal competente. VI. Conclusiones. 


\section{Antecedentes de hecho y la instancia de origen}

1. Este comentario versará sobre dos aspectos clave mencionados por el auto y son determinar si existe cláusula arbitral y la importancia de la voluntad de someterse a arbitraje. Además, también se tratará un tercer punto no mencionado por el tribunal pero sí invocado por una de las partes relativo al tema de la vulneración de la tutela judicial efectiva por parte del tribunal cuando éste se inhibe de conocer el asunto y remite a arbitraje.

2. Antes de avanzar con el estudio hay que describir la situación con la que se encontró la Audiencia de Barcelona. Ante ella se presentó un recurso de apelación que traía causa de un auto dictado por el Juzgado de Primera Instancia $n^{\circ} 32$ de Barcelona. Según el caso de autos la empresa HYLA Trade D. o. o. (empresa eslovena) formula demanda de reclamación de cantidad frente a BS IMPORT PROYECT, S.L. (empresa española) ante el Juzgado de Primera Instancia. Alega la actora que ambas partes habían celebrado un contrato de importación, en el que la empresa española se comprometía a organizar la venta de los productos de la empresa eslovena en España. BS IMPORT realiza un pedido a HYLA cuyo montante ascendía a $136.700 €$. Como parte del pacto el pago se realizaría con carácter previo al envío de los productos pero, sobre la base de la confianza fruto de años de relaciones, se entregaron las mercancías antes de realizarse el pago. La mercancía llegó en fecha 5 de Julio de 2016, pero la entidad importadora no procedió al pago. Sin embargo, BS IMPORT realizó una transferencia meses más tarde pero por un importe menor del acordado. Decidieron fijar un calendario de pagos y la demandada realizó varios pagos, aunque finalmente incumplió el compromiso adquirido. En total abonó $20.000 €$ que, descontados de la cantidad total debida, hace un importe pendiente de abono de $101.700 €$.

3. Frente a esta demanda BS IMPORT presentó una declinatoria y alegó la falta de competencia internacional del Juzgado de Primera Instancia, por existir en el contrato una cláusula que remitía a arbitraje. Contestó la actora que no existía tal cláusula en el contrato de importación y que de haber querido someter un posible litigio a arbitraje lo habrían hecho de forma clara. Añadió que la cláusula contenida en el contrato, de ser considerada cláusula arbitral, debería ser inoperante e ineficaz por contar con lagunas e irregularidades insalvables.

4. El Ministerio Fiscal emitió un informe y en él trató la cuestión planteada en la declinatoria, relativa a la existencia de una cláusula arbitral. En base a ello, declaró la existencia de la cláusula y, por tanto, la ligación del asunto a arbitraje, por lo que se debería remitir a esta vía y no conocer en el orden jurisdiccional. Tras ello, el Juzgado dictó un auto en el que estimaba la declinatoria planteada y confirmaba su falta de competencia, por lo que declaró el sobreseimiento de las actuaciones y su remisión a arbitraje, así como la imposición de costas. Contra esta resolución la actora presentó recurso de alzada frente a la Audiencia Provincial de Barcelona en el que alegaba la falta de motivación y la infracción de la normativa y jurisprudencia aplicables con vulneración de la tutela judicial efectiva del art. $24 \mathrm{CE}$. Finalmente, emite la Audiencia Provincial un auto en el que estima parcialmente el recurso de apelación interpuesto por HYLA, revoca el pronunciamiento de costas, pero confirma la declinatoria, de igual modo que hizo el Juzgado de Primera Instancia, por lo que considera que sí existe cláusula arbitral.

\section{El análisis de la cláusula arbitral. Lo que tendría que haber sucedido}

5. En el caso de autos se discute si existe una cláusula arbitral y si las partes querían incorporarla. Esto se traduce en la necesidad de realizar un estudio pormenorizado sobre la forma de la cláusula arbitral y la voluntad real de las partes de incorporar esa cláusula.

6. Antes de comenzar hay que poner de relieve que la Unión Europea excluye al arbitraje de las "Alternative Dispute Resuolutions" (ADR), ya que no es una modalidad alternativa de solución de conflictos con la que se designa a otros procedimientos extrajudiciales de resolución en los que también dirime la 
cuestión un tercero imparcial, como es la mediación ${ }^{l}$. Esto se debe a su "cercanía" al procedimiento judicial y a que el objetivo de la sentencia arbitral, o laudo, es la de sustituir la decisión de la justicia. ${ }^{2}$ Las partes deciden someter los posibles litigios, presentes o futuros, a arbitraje a través de un acuerdo arbitral, que es “(...) el acuerdo por el cual dos o más partes deciden someter a arbitraje la resolución de sus controversias.". Además, dicho acuerdo puede constar en una cláusula inserta en un contrato, denominada cláusula arbitral, o ser un acuerdo propio e independiente, el cual haya sido referenciado por las partes a través de otras comunicaciones o que aparezca adjunto al contrato, calificado en este caso como convenio arbitral ${ }^{3}$.

7. Además, de la mano de Calvo Caravaca y Carrascosa González se puede dividir el objeto del convenio arbitral en $\operatorname{dos}^{4}$. Por un lado, puede que el convenio arbitral consista en la resolución de un litigio ya existente entre las partes, por lo que se le denominará como "compromiso arbitral"; o bien en la resolución de un litigio futuro, en cuyo caso recibe el nombre de "cláusula compromisoria". La distinción es relevante en aquellos ordenamientos jurídicos estatales que mantienen una actitud prohibitiva o restrictiva de las cláusulas compromisorias ${ }^{5}$.

\section{La forma de la cláusula arbitral: existencia y validez}

8. La cláusula de la que trae causa el litigio indica que "21. Este contrato deberá integramente interpretarse y aplicarse de conformidad con las Leyes de la República de Eslovenia. El arbitraje tendrá lugar en Ljubljana, República de Eslovenia". Por tanto, hay que hacer un doble análisis en cuanto a la forma y versará sobre la existencia de la cláusula y su validez.

9. Se debe partir del hecho de que las dos empresas tienen sus domicilios en Estados distintos. Esta precisión ya indica algo que debe ser tenido en cuenta, y es que una de las partes está sometida a una ley distinta de la española, por lo que tiene la consideración de extranjera. En España el arbitraje se regula en Ley 60/2003, de 23 de diciembre, de Arbitraje 6 , la cual advierte en su art. 3 que " 1 . El arbitraje tendrá carácter internacional cuando en él concurra alguna de las siguientes circunstancias: a) Que, en el momento de celebración del convenio arbitral, las partes tengan sus domicilios en Estados diferentes. (...) ${ }^{7}$. Por

${ }^{1}$ LIBRO VERDE sobre las modalidades alternativas de solución de conflictos en el ámbito del derecho civil y mercantil. 1. Panorama global. 1.1.2. [2]. https://eur-lex.europa.eu/legal-content/ES/TXT/HTML/?uri=CELEX:52002DC0196\&from=PL

${ }^{2}$ O. D. Franco Conforti, “Aspectos básicos y prácticos del arbitraje comercial internacional”. La Ley 5409/2015. 24 de septiembre de 2015. Pág. 6.

${ }^{3}$ M. VIRgós, "El Convenio Arbitral en el Arbitraje Internacional”. Actualidad Jurídica Uría Menéndez/ 14-2006. Pág. 13.

${ }^{4}$ A.-L- Calvo Caravaca/ J. Carrascosa González (Directores), "Derecho del comercio internacional”, Ed. Colex, Madrid, 2012, ISBN: 978-84-8342-363-9, pp. 2084 y A.-L. Calvo Caravaca/ J. Carrascosa González, “Arbitraje privado internacional", pp. 1722-1835.

${ }^{5}$ Indican los autores que en Derecho español no existe diferencia de tratamiento jurídico entre la "cláusula compromisoria" y el "compromiso arbitral". La Ley 60/2003 se refiere, exclusivamente, al "convenio arbitral" (art. 9.1 LArb 2003). Añaden además que " 1 ) En el comercio internacional actual es más frecuente la "cláusula compromisoria" (R. David, P. Schlosser). Es una cláusula cuyo otorgamiento es sencillo. En efecto, en este caso, el recurso al arbitraje se incluye como una cláusula más de un contrato cuyo objeto principal es otro, una compraventa, un suministro, etc. Además, la cláusula compromisoria comporta una gran seguridad jurídica para las partes. Éstas, desde el primer momento, son conscientes de que las diferencias surgidas de la interpretación o ejecución del contrato concluido por ellas, serán resueltas mediante un arbitraje y no mediante los Tribunales estatales de Justicia (J. D. GONZÁLEZ CAMPOS, R. DAVID)."

${ }^{6}$ Ley 60/2003, de 23 de diciembre, de Arbitraje. (BOE núm. 309, de 26 de diciembre de 2003. Ref. BOE-A-2003-23646)

${ }^{7}$ Los tres requisitos que el art. 3 Ley 60/2003 ofrece para determinar la internacionalidad del arbitraje son a) que las partes tengan domicilios en Estados diferentes al momento de realizar el convenio; b) Que el lugar del arbitraje, el de cumplimiento de una parte sustancial de las obligaciones de la relación jurídica de la que dimana la controversia o el lugar con el que ésta tenga una relación más estrecha, esté fuera del Estado en el que las partes tienen sus domicilios; y, finalmente, c) que la relación jurídica de la que dimane la controversia afecte a intereses del comercio internacional.

Es interesante apreciar que el precepto utiliza el término "alguna" antes de hacer la relación de los tres requisitos. Esto significa que se tratan de puntos de conexión alternativos, no en cascada o todos de obligatoria observancia. Por tanto, no es necesario que se aprecien todos los requisitos, pues basta con que haya uno o dos y el precepto le dará la consideración de arbitraje internacional. 
tanto, se debe concluir que se trata de un arbitraje internacional ${ }^{8}$. Dicho esto habrá que acudir a las leyes aplicables al arbitraje internacional.

10. Las dos normas jurídicas encargadas de regular el arbitraje cuando éste contiene elementos extranjeros son, de un lado, el Convenio de Ginebra de 1961 sobre Arbitraje Comercial Internacional ${ }^{9}$ (CG en adelante) y, de otro lado, el Convenio de Nueva York de 1958 sobre el Reconocimiento y la Ejecución de las Sentencias Arbitrales Extranjeras ${ }^{10}$ (CNY en adelante). Puesto que ambos convenios han sido suscritos por España y han sido publicados en el BOE pasan a formar parte del ordenamiento jurídico interno ${ }^{11}$. Esto significa que son de preferente aplicación frente a la normativa nacional.

11. El art. II CNY se divide en tres apartados. El primero establece que cada Estado contratante reconocerá el acuerdo por escrito conforme al cual las partes hayan decidido someter sus diferencias, presentes o futuras, respecto a una determinada relación jurídica a arbitraje. El apartado 2 define qué debe entenderse por "acuerdo por escrito" y es "(...) una cláusula compromisoria incluida en un contrato o un compromiso, firmados por las partes o contenidos en un canje de cartas o telegramas". El tercer apartado insta a los tribunales del Estado al que se le someta el litigio a remitirlo a arbitraje, salvo que compruebe que el acuerdo es nulo, ineficaz o inaplicable.

12. Cabe ahora preguntarse si esta exigencia de constar por escrito es una formalidad ad solemnitatem o ad probationem. La forma solemne es un requisito de validez del acto jurídico y cumple con una función de forma esencial; por su parte, la forma probatoria no constituye un requisito de validez, sino que se puede prescindir de ella sin que por eso se vea afectada la validez y eficacia del acto ${ }^{12}$.

13. De la letra del art. II CNY se puede deducir que para éste se trata de un requisito ad solemnitatem, por lo que la apreciación de la forma escrita supone un requisito para determinar la validez de la cláusula o convenio arbitral. Esto es así debido a que no ofrece ninguna otra opción de inclusión y, puesto que se trata de un convenio de aplicación erga omnes, es un requisito que deberá ser cumplido para reconocer la existencia de la cláusula. ${ }^{13}$

8 "Un arbitraje se dice internacional porque trasciende de la esfera de un único Estado y presenta vínculos o conexiones con otros Estados". (M. VIRGÓs. 2006, 23).

${ }^{9}$ Traspuesto en España en el BOE núm. 238, de 4 de octubre de 1975, págs. 20985 a 20988. (Ref. BOE-A-1975-20601.)

${ }^{10}$ Traspuesto en España en el BOE núm. 164, de 11 de julio de 1977, págs. 15511 a 15512. (Ref. BOE-A-1977-15727.)

${ }^{11}$ Esta previsión se establece en la Constitución Española, más concretamente en el art. 96.1 CE el cual indica que "Los tratados internacionales válidamente celebrados, una vez publicados oficialmente en España, formarán parte del ordenamiento interno.". No hay que dejarse llevar por la terminología y considerar que únicamente los tratados pueden considerarse como normativa interna, pues "Ello no significa que resulte imposible la introducción de otras normas internacionales, sino más bien que la integración de las mismas habrá de verificarse en los términos previstos en los tratados de los que deriven, siempre y cuando éstos formen parte del ordenamiento español. La expresión "tratado" no comprende todas las posibles normas internacionales. El artículo 2.1.a) del Convenio de Viena sobre Derecho de los Tratados, de 1969, define al tratado como "un acuerdo internacional celebrado por escrito entre Estados y regido por el Derecho internacional, ya conste en un instrumento único o en dos o más instrumentos conexos, y cualquiera que sea su denominación particular" (J.L. ReQueJo PAGEs. "Consideraciones en torno a la posición de las normas internacionales en el Ordenamiento español”. Revista Española de Derecho Constitucional. Año 12. Núm. 34. Enero-abril 1992. Pág. 48.). Por ello, los convenios también forman parte del Ordenamiento Jurídico interno.

${ }^{12}$ C.D. Cortez Pérez. "La forma del acto jurídico en el Código Civil peruano de 1984”. Memorando de Derecho. 2012. Págs. 210 y 212

${ }^{13}$ Cuestión distinta es si se estudia la cláusula a la luz del Convenio de Ginebra, pues su art. I.2.a) in fine indica que "(...) en las relaciones entre Estados cuyas leyes no exijan la forma escrita para el acuerdo o contrato arbitral, [se considera acuerdo o compromiso arbitral] todo acuerdo o compromiso estipulado en la forma permitida por dichas leyes. "Flexibiliza así este requisito para el supuesto en que uno de los Estados no exija la forma escrita, por lo que lo convierte en un requisito ad probationem, pero habrá que estar a lo que indique la normativa de ese Estado sobre forma del convenio arbitral. Sin embargo, no hay que olvidar que el CG opera inter partes (M. VIRGÓs. "El convenio arbitral en el arbitraje internacional". Actualidad jurídica Uría Menéndez/ 14-2006. Artículos. Pág. 24), por lo que sólo será aplicable y oponible entre Estados que lo hayan adoptado. Además es un convenio concebido como complementario del CNY 1958, donde algunas de sus reglas modifican expresamente las relaciones entre los Estados contratantes (M. VIRGOs. "El convenio arbitral en el arbitraje internacional". Actualidad jurídica Uría Menéndez/ 14-2006. Artículos. Pág. 15). 
14. Una vez determinada la forma, hay que estudiar el tema de la validez de la cláusula. El art. VI CG, en relación con la competencia de los tribunales estatales, establece que "2. Al examinar y pronunciar resolución sobre la cuestión de la existencia o validez del acuerdo o compromiso arbitral, los tribunales nacionales de los Estados Contratantes ante los cuales se hubiere promovido dicha cuestión, deberán, en lo referente a la capacidad jurídica de las partes, atenerse a la Ley que les sea aplicable a éstas, y en lo concerniente a las restantes materias, decidirán: a) Según la ley a que hayan sometido las partes el acuerdo o compromiso arbitral; (...)”

15. En función de este precepto la ley encargada de determinar la existencia y validez de la cláusula arbitral es la ley a la que las partes hayan sometido el litigio. En este sentido, la ley elegida es la ley eslovena, por lo que será ella la encargada de decidir sobre los requisitos que deben observarse para considerar la cláusula válida.

16. A este respecto, el art. 10 de la Ley de Eslovenia manifiesta que "1) (...) El acuerdo de arbitraje puede presentar la forma de una cláusula inserta en un contrato o de un acuerdo independiente". Por tanto, puesto que permite que presente la forma de cláusula inserta en un contrato, la cláusula del supuesto tratado sería válida y existente conforme a la ley aplicable.

\section{La voluntad de las partes}

17. La siguiente circunstancia que se discute y que habría que abordar es si existía o no intención de incorporar la cláusula de sumisión al arbitraje o, como declara HYLA, “(...) la voluntad de las partes fue la de suprimir la cláusula arbitral que se incluia en el modelo de contrato que ella misma redactó, pero por un error material, se omitió eliminar su última frase".

18. Como ya se ha explicado, la ley aplicable a la cláusula arbitral es la ley eslovena. Por consiguiente hay que acudir a su legislación nacional en busca de los requisitos para validez de los contratos. $\mathrm{El}$ art. 82 del Código de las Obligaciones esloveno determina que las disposiciones del contrato se interpretarán como se leen. El apartado segundo expresa que si hay alguna disposición controvertida "no será necesario ceñirse al significado literal de las expresiones utilizadas, pero será necesario identificar las intenciones comunes de las partes contratantes e interpretar la disposición de manera que cumpla con los principios de la ley de obligaciones establecida en el presente código" ${ }^{14}$. Esas "intenciones comunes de las partes" es la voluntad que tenían las partes al incluir una determinada cláusula en el contrato.

19. De los datos con que se cuenta no se puede valorar que la intención de las partes fuese distinta a la inclusión de la cláusula arbitral, pues no hay prueba alguna que pruebe que esa no fuese su voluntad real y que sólo se trataba de un mero error material.

20. Por ende, la cláusula arbitral debe entenderse como puesta, existente y válida, por lo que el tribunal debe remitir la cuestión a arbitraje.

\section{El caos normativo del que hace gala la AP. Lo que de verdad pasó}

21. A continuación, se va a realizar un análisis de la actuación de la AP y su razonamiento jurídico, para comprobar que el Derecho Internacional Privado es ese gran desconocido de los tribunales españoles.

\footnotetext{
${ }^{14}$ Traducción libre del autor. El texto en inglés dicta "(2) In the interpretation of disputed provisions it shall not be necessary to adhere to the literal meaning of the expressions used, but shall be necessary to identify the contracting parties' common intentions and interpret the provision so as to comply with the principles of obligational law set out in the present code.". http://www.uil-sipo.si/fileadmin/upload_folder/zakonodaja/povezano/Obligations-Code_Slovenia_2001.pdf
} 


\section{La forma de la cláusula arbitral}

22. Tras una exposición de los hechos ocurridos, el tribunal comienza su explicación con la aplicación del art. 39 de la Ley de Enjuiciamiento Civil español, que permite al demandado la denuncia de la falta de competencia internacional por estar sometido el litigio a arbitraje. Esta denuncia se realizará a través de la declinatoria. A continuación, asienta el problema que va a acometer, que es la existencia del convenio arbitral que ha dado lugar a la estimación de la declinatoria ${ }^{15}$. Prosigue su desarrollo con la trascripción de la cláusula arbitral fruto de la controversia y expone que "La cláusula transcrita, si contuviera un convenio arbitral, -eso es precisamente lo que se discute-, integraría un supuesto de arbitraje internacional, de acuerdo con el art. 3.1. a) de la Ley 60/2003, de 23 de diciembre, en relación con el art 1. a) del Convenio Europeo sobre Arbitraje Comercial Internacional hecho en Ginebra el 21 de abril de 1961, a cuyo régimen jurídico se encontraría sometido, siendo aplicable al mismo, igualmente, el Convenio de Nueva York de 1958 sobre reconocimiento y ejecución de sentencias arbitrales extranjeras".

23. Añade que ambos convenios han sido suscritos por España y han cumplido las formalidades internas correspondientes, por lo que pasan a formar parte del ordenamiento jurídico interno. Para completar esta idea indica que son de prevalente aplicación a las normas nacionales cuando se den los supuestos de tráfico externo que configuran su ámbito de aplicación. Asimismo, apunta que tales convenios han sido suscritos por Eslovenia.

24. Tras esta acertada explicación, con alguna salvedad conceptual, enuncia la sentencia del Tribunal Supremo de 14 de noviembre de 2007 y lo hace para señalar que, puesto que esta sentencia se refiere a los dos convenios internacionales y los trata de preferente aplicación, eso mismo es lo que hará ella. Por tanto, aplica el art. II CNY, que define qué se entenderá por acuerdo por escrito. No tiene mucho sentido para el caso mencionar esta sentencia, pues no añade nada nuevo a lo que ya había dicho la propia AP.

25. Se plantea entonces la cuestión de la Ley aplicable para determinar la eficacia, validez o nulidad del convenio arbitral. Para solucionar tal pregunta acude al art. VI.2 CG, el cual determina que la ley aplicable será aquella a la que las partes hayan sometido el acuerdo o compromiso arbitral. Concluye la AP que “(...) la ley con arreglo a la cual debería analizarse si la cláusula del contrato que invoca la demandada contiene un convenio arbitral válido sería la ley eslovena".

26. El siguiente paso sería aplicar la Ley eslovena y este apartado estaría solucionado. Sin embargo, la AP decide, por algún motivo desconocido, que lo mejor es aplicar la Ley española de arbitraje, concretamente el art. 9. Tras hacer una trascripción del contenido del precepto explica que "El art. 9.6 LA no es totalmente coincidente en este punto con lo que establece el art. 6 del Convenio de Ginebra. Sin embargo, en el caso de autos no se produce ningún problema de discrepancia de normas, porque ambas normativas, la eslovena y la española, tienen un contenido similar en cuanto al convenio arbitral ${ }^{16}$ ". La mención a la legislación española resulta ilógica e inútil, pues ha declarado que la Ley aplicable es la eslovena, por lo que poco o nada importa el contenido de la normativa española para decidir la validez de la cláusula arbitral.

27. Finalmente aplica la norma eslovena, concretamente el art. 10 de la Ley de Arbitraje eslovena, la cual corrobora la inclusión del acuerdo de arbitraje en forma de cláusula en el contrato.

\footnotetext{
${ }^{15}$ Ya se ha puesto de manifiesto en el epígrafe anterior que el acuerdo mediante el cual las partes se someten a arbitraje puede ser en forma de cláusula inserta en un contrato (cláusula arbitral), contrato propiamente dicho, el cual es más extenso que la cláusula (convenio arbitral), o incluso en forma de compromiso (cláusula compromisoria o compromiso arbitral). Aunque el tribunal habla de la existencia del convenio, en realidad se refería a la cláusula arbitral.

${ }^{16}$ Art. 9.6 Ley 60/2003: "6. Cuando el arbitraje fuere internacional, el convenio arbitral será válido y la controversia será susceptible de arbitraje si cumplen los requisitos establecidos por las normas jurídicas elegidas por las partes para regir el convenio arbitral, o por las normas jurídicas aplicables al fondo de la controversia, o por el derecho español".
} 


\section{La voluntad de las partes}

28. Asentado el requisito de forma, la siguiente cuestión a la que se enfrenta el tribunal es decidir si las partes querían incluir la cláusula o no. Menciona como punto de partida de su exposición que ambas leyes de arbitraje, española y eslovena, están inspiradas en la Ley Modelo elaborada por la Comisión de las Naciones Unidas para el Derecho Mercantil Internacional, de 21 de junio de 1985 (Ley Modelo CNUDMI/ UNICTRAL). Tras esto indica que la Exposición de Motivos de la Ley de Arbitraje española pone de relieve que "(...) la voluntad de las partes sobre la existencia del convenio arbitral se superpone a sus requisitos de forma".

29. Remite también a la sentencia del Tribunal Supremo 607/2010, de 7 de octubre ${ }^{17}$ y al auto del TSJC de 6 de mayo de 2016, las cuales alegan que lo decisivo para la validez del convenio arbitral es la voluntad inequívoca de las partes de incluir esa cláusula. Por tanto, la AP se basa en esta afirmación cuando sostiene que “(...), la cuestión radicará en determinar si la fórmula utilizada por las partes pone de manifiesto su voluntad clara de someter la cuestión a arbitraje". Y para determinar esa clara voluntad acude a los artículos 1281 y 1282, a sensu contrario, del Código Civil español y concluye que no hay indicios en el contrato ni en los actos coetáneos o posteriores a éste que indique que la intención era otra distinta a la inclusión de la cláusula arbitral.

30. Con fundamento en todo lo anterior, determina la AP que no hay prueba alguna que demuestre que la voluntad de las partes era la de suprimir el acuerdo, como alega la actora. Y puesto que la primera frase de la cláusula indica la sumisión a un determinado ordenamiento para la resolución de las controversias, y la segunda hace referencia al lugar en el que se llevará a cabo el arbitraje, todo conduce a pensar que sí se quiso incluir la cláusula arbitral.

31. Injustificada y totalmente desacertada es la definición que merece la argumentación de la AP en este aspecto. Tras haber comprobado que la Ley aplicable es la eslovena mantiene su empeño en aplicar la norma española. Pero no sólo eso, sino que también utiliza jurisprudencia española para apoyar su equivocada explicación. Por mucha pasión que se sienta hacia los elementos legislativos patrios, si la Ley aplicable es otra, no hay nada que hacer más que rendirse a la evidencia y aplicar la otra ley.

\section{Principios constitucionales en el arbitraje: el derecho de defensa}

32. Un último aspecto que hay que mencionar, aunque la AP no lo estudia, es el hecho esgrimido por la recurrente sobre una posible indefensión debida a la vulneración de la tutela judicial efectiva del art. 24 de la Constitución Española, en tanto en cuanto el Juzgado de Primera Instancia no entró a conocer el asunto y les remitió a arbitraje.

33. Ya se ha dicho al principio de este estudio que la Unión Europea no incluye el arbitraje en el grupo de los ADR por su cercanía al procedimiento judicial ordinario. Esta afirmación se puede apreciar en el hecho de que el árbitro goza de independencia e imparcialidad, además de poder ser recusado por las partes. Además, el procedimiento arbitral también presenta garantías para las partes como los principios de igualdad, audiencia y contradicción o los de colegialidad y secreto de las deliberaciones ${ }^{18}$.

34. En este sentido, la sentencia del Tribunal Europeo de Derechos Humanos en el asunto Suda c. République Tchèque ${ }^{19}$ estudia la sumisión a arbitraje bajo el prisma del art. 6 del Convenio Europeo de

\footnotetext{
${ }^{17}$ STS 607/2010, de 7 de octubre. ECLI: ES:AN:2010:607

${ }^{18}$ Para un estudio en mayor profundidad de los principios rectores de los árbitros y del procedimiento arbitral acudir al libro de M. GÓMEZ Jene. "Arbitraje Comercial Internacional”. Ed Civitas. 2018. Concretamente a sus capítulos VIII y IX.

${ }^{19}$ STEDH, 28 de octubre de 2010, núm. 1643/06. ECLI: CE: ECHR:2010: 1028JUD000164306
} 
Derechos Humanos, que habla sobre el derecho a un proceso equitativo ${ }^{20}$. Esto es importante puesto que "El Tribunal recuerda que el derecho al acceso a un tribunal (...) no implica, en materia civil, la obligación de someterse a una jurisdicción de tipo clásico, integrada en las estructuras judiciales ordinarias de un país (...). El artículo 6 no se opone a la creación de tribunales arbitrales con el fin de juzgar ciertas diferencias de naturaleza patrimonial que enfrente a particulares. Nada impide a los justiciables a renunciar a su derecho a un tribunal en favor de un arbitraje, a condición de que esa renuncia sea libre, lícita e inequívoca (...).

35. Así pues, no se podrá considerar que ha existido una indefensión por parte del tribunal ordinario al inhibirse de conocer un asunto, siempre y cuando haya una cláusula o un convenio arbitral que remita a las partes a arbitraje. Ambas estructuras tienen la potestad para conocer de los asuntos a los que les sometan las partes, siempre que sean materias de libre disposición. Por lo que al no haber prueba que demuestre la intención de no incluir esa cláusula arbitral, se considerará válida y puesta, y la remisión a arbitraje no supondrá ninguna vulneración del art. 24 CE.

\section{Régimen jurídico de la elección de la Ley aplicable al convenio arbitral y de la Ley aplicable a la elección del tribunal competente}

36. La cláusula arbitral goza de autonomía respecto del contrato en el que se encuentra inserta. Esta afirmación se basa en el principio de separabilidad o autonomía, que consiste en proclamar la independencia que ostenta la cláusula frente al contrato principal. Lo anterior se traduce en que ésta no se verá afectada por las vicisitudes que puedan perjudicar la existencia o validez del contrato que la contiene ${ }^{21}$.

37. El principio anterior es una consecuencia de la admisión de la autonomía de la voluntad. Ésta consiste en el derecho subjetivo de las partes de decidir la ley aplicable al convenio ${ }^{22}$. Tal ley regulará la forma, capacidad y validez del acuerdo por el cual dos o más partes deciden someter una controversia a arbitraje internacional ${ }^{23}$. Además, en el contexto del arbitraje, "La autonomía de la voluntad (...) no tiene un límite temporal. De hecho, [las partes] podrán modificar decisiones previamente tomadas y con independencia del criterio del colegio arbitral"24.

38. Si se ponen en relación ambos principios, se puede afirmar que las partes pueden elegir el derecho que regulará la cláusula arbitral y el fondo de la cuestión, tal y como se reconoce en el art. V.1.a) $\mathrm{CNY}^{25}$. Se ofrece a las partes libertad para decidir la ley que el árbitro debe aplicar para solventar la cuestión y que el juez debe estudiar para determinar si existe algún vicio y, en su caso, no corresponderá el reconocimiento del consecuente laudo.

\footnotetext{
${ }^{20}$ Art. 6 CEDH: "1. Toda persona tiene derecho a que su causa sea oída equitativa, públicamente y dentro de un plazo razonable, por un Tribunal independiente e imparcial, establecido por ley, que decidirá los litigios sobre sus derechos y obligaciones de carácter civil o sobre el fundamento de cualquier acusación en materia penal dirigida contra ella. (...)”

${ }^{21}$ R.J. CAVIANo. "El contrato de arbitraje y su autonomía respecto del contrato que lo contiene." Derecho y Ciencias Sociales. Octubre 2015. No 13. Pág. 19.

${ }^{22}$ O. Casanovas y La Rosa. “La autonomía de la voluntad en Derecho Internacional Privado”. 1976. Pág. 1004.

${ }^{23}$ H. M. Medina CAsas. "La Ley aplicable al pacto arbitral: incertidumbre en contravía de las bases del arbitraje internacional”. Arbitraje PUCP. 2017. Pág. 142.

${ }^{24}$ M. GÓmez Jene, “Arbitraje Comercial Internacional”. Ed. Civitas. 2018. Pág. 286.

${ }^{25}$ Art. V.1.a) CNY: "1. Sólo se podrá denegar el reconocimiento y la ejecución de la sentencia, a instancia de la parte contra la cual es invocada, si esta parte prueba ante la autoridad competente del país en que se pide el reconocimiento y la ejecución: a) Que las partes en el acuerdo a que se refiere el artículo II estaban sujetas a alguna incapacidad en virtud de la ley que les es aplicable o que dicho acuerdo no es válido en virtud de la lev a que las partes lo han sometido, o si nada se hubiera indicado a este respecto, en virtud de la ley del país en que se haya dictado la sentencia;" (Negrita y subrayado incluido por el autor).
} 
39. Sin embargo, esta libertad no es absoluta pues encuentra su límite, primero, en la forma que debe tener la cláusula para considerarse válida, recogida en el art. II CNY; y, segundo, en la arbitrabilidad de la materia y el orden público. En este sentido, el art. V.2 CNY prevé ambos motivos como causas de denegación del reconocimiento y exequátur del laudo. Esta denegación se hará en base a la Ley del país en el que se está solicitando el reconocimiento, por lo que entra en juego otra ley aplicable a la interpretación de la cláusula arbitral. El juez examinará la cláusula a la luz de su ley nacional y será en base a ella con la que decida si la cláusula es válida o no y, por ende, otorgará el reconocimiento o lo denegará.

40. Interesante cuestión es la comparativa entre el régimen hasta aquí explicado y la sumisión realizada por las partes a un tribunal estatal de justicia. Esta previsión se encuentra en el art. 25 del Reglamento (UE) n ${ }^{\circ}$ 1215/2012 del Parlamento Europeo y del Consejo, de 12 de diciembre de 2012, relativo a la competencia judicial, el reconocimiento y la ejecución de resoluciones judiciales en materia civil y mercantil, más conocido como Reglamento Bruselas I-bis (RBI-bis en adelante).

41. El precepto se titula "Prórroga de la competencia", puesto que prorroga o extiende la competencia judicial internacional a tribunales que, de otro modo, no tendrían competencia para conocer del litigio. Este artículo contempla, en definitiva, la viabilidad de que las partes se sometan a tribunales estatales que no serían competentes. "El acuerdo de sumisión es un pacto entre las partes de una relación jurídica en cuya virtud, éstas determinan el órgano jurisdiccional que será competente para conocer de los litigios que eventualmente pudieran surgir como consecuencia de ciertas obligaciones asumidas por las partes" ${ }^{26}$.

42. El artículo establece que el acuerdo debe constar por escrito, o verbalmente con confirmación escrita. También considera la posibilidad de determinar la forma en función de los hábitos que las partes tengan establecidos entre ellas o, en el ámbito del comercio internacional, en una forma habitual a los usos que las partes conozcan o deban conocer. Añade que se considerará por escrito "toda transmisión efectuada por medios electrónicos que proporcione un registro duradero del acuerdo".

43. De lo hasta aquí dicho se puede apreciar que es un pacto cuya naturaleza radica también en la autonomía de la voluntad, pues depende de las partes su concierto. Asimismo, también exige que se celebre por escrito, pero añade dos formas más que la norma arbitral no contempla y son una forma que se ajuste a los hábitos de las partes y cualquier otra que sea habitual en el ámbito del comercio internacional. Se proponen así dos posibilidades más para determinar la validez que no se consideran en el art. II.2 CNY.

44. Además, el art. 25.5 RBI- bis indica que el acuerdo atributivo que forme parte de un contrato se considerará un acuerdo independiente y su validez no podrá ser impugnada por la sola razón de la invalidez del contrato. Al igual que ocurría con la cláusula arbitral y el principio de autonomía o separabilidad, se considera el acuerdo atributivo como un acuerdo independiente del contrato principal. El RBI- bis no añade nada distinto al CNY, pues ambas ofrecen el mismo tratamiento a los acuerdos celebrados por las partes.

45. Finalmente, el art. 25.1 RBI- bis expone que si las partes han acordado que un determinado órgano jurisdiccional de un Estado miembro será el competente para conocer del posible litigio que pueda surgir, éste será competente "a menos que el acuerdo sea nulo de pleno derecho en cuanto a su validez material según el Derecho de dicho Estado miembro". Si bien no emplea los mismos términos, lo cierto es que somete la validez del acuerdo a su estudio en función de la ley del Estado al que pertenece el tribunal elegido por las partes.

${ }^{26}$ A.-L- Calvo Caravaca/ J. Carrascosa González. "Derecho Internacional Privado. Volumen I". Decimoquinta Edición. Ed. Comares. 2014. Pág 218. 
46. Esta remisión incluye también los principios de arbitrabilidad y orden público del Estado cuyos tribunales serán ahora competentes. Pero además a las normas sobre conflictos de leyes de dicho Estado miembro ${ }^{27}$. Debido a lo anterior, la lupa bajo la cual será analizado el acuerdo atributivo implica más factores a tener en cuenta que la que examina la cláusula arbitral.

47. En base a todo lo anterior se puede afirmar que ambas normativas son en esencia muy similares. Ambas parten de la autonomía de la voluntad de las partes. Sin embargo, el RBI- bis permite dos formas añadidas a la forma escrita. Por su parte, el CNY sólo ofrece dos opciones para negar el reconocimiento, que no anular la cláusula, lo cual limita el abanico de posibilidades que un Estado puede alegar para no reconocer la cláusula como válida, mientras que el RBI- bis permite al juez acudir a toda la ley material del Estado cuyos tribunales han adquirido competencia.

48. No obstante, hay una gran diferencia entre una y otra regulación y es el hecho de que se puede elegir la ley aplicable a la cláusula, es decir, la ley que se aplica al contrato en cuya virtud se someten las partes a la decisión de un arbitraje, la cual puede ser distinta de la ley aplicable al procedimiento y al fondo; pero no la ley aplicable al acuerdo atributivo. Tal y como dicen A-L. CALvo CARAVACA y J. CARRASCOSA GONZÁLEZ "Aunque el acuerdo atributivo de competencia es un "contrato", las partes no pueden elegir la Ley aplicable a dicho contrato. El art. 25 RB-I bis impone, imperativamente, la aplicación del Derecho material del Estado miembro cuyos tribunales han sido elegidos por las partes. Como escribe J.-P. BERAUDO, la cláusula de elección de tribunal es autónoma (= separable) respecto del contrato en el que se inserta, pero las partes carecen de autonomía de voluntad conflictual para señalar la Ley aplicable a la validez material de dicha cláusula: autonomía sin autonomía. "28. Por su parte, en la cláusula arbitral, las partes puede elegir la ley aplicable al propio convenio.

49. Esto se debe a que el tribunal está sometido a los poderes del Estado y es ante éste que tiene que responder, por eso necesita la ley material nacional para comprobar que se le ha atribuido correctamente la competencia para conocer y que ese acuerdo de sumisión no vulnera ninguno de sus principios, como seguridad jurídica, orden público, etc. Por contra, el arbitraje es un órgano "anacional", se dice que está desligado de cualquier ordenamiento jurídico, no tiene que responder ante nadie, únicamente ante las partes, por lo que son ellas las que establecen cómo darle la competencia y él, en base a esas directrices dadas, va a confirmar que se ha hecho correctamente. Así pues, el tribunal está incardinado en un sistema estatal y debe velar por proteger sus intereses, por eso es esa ley quien le dará las pautas a seguir para verificar que el acuerdo atributivo es correcto; en cambio, el arbitraje es independiente, no está sometido a ningún ordenamiento jurídico, por lo que son las propias partes las que van a regular todos los aspectos, incluida la ley aplicable a la cláusula arbitral.

\section{Conclusiones}

50. La fuerte tendencia de los tribunales por "nacionalizar" asuntos que son obviamente internacionales ha quedado más que patente en el supuesto tratado. El hecho de que la AP se empeñe en aplicar la legislación y jurisprudencia española a un supuesto con un claro elemento extranjero pone de manifiesto el poco conocimiento que se tiene por parte de los tribunales españoles de los instrumentos internacionales con los que cuenta España, a pesar de haber sido ratificados, o del DIPriv. en general. Esto puede deberse, pero no justificarse, en el temor de incurrir en una situación de inseguridad jurídica. Puesto que los tribunales no saben qué ley han de aplicar, ni los resultados que ello puede conllevar, se muestran reacios a la remisión al Derecho extranjero. Igualmente, es probable que recelen por si su apli-

\footnotetext{
${ }^{27}$ A.-L- Calvo Caravaca/ J. Carrascosa González. "Derecho Internacional Privado. Volumen I". Decimoquinta edición. Ed. Comares. 2014. Pág. 229

${ }^{28}$ A.-L- Calvo Caravaca/ J. Carrascosa GonzÁlez. "Derecho Internacional Privado. Volumen I". Decimoquinta edición. Ed. Comares. 2014. Pág. 230
} 
cación conlleva a la vulneración del orden público español. Del supuesto estudiado se pueden extraer varias reflexiones.

Primero. La precisión lingüística y terminológica es el sello de identidad del buen jurista. Sin embargo, la AP parece confusa en tanto utiliza de forma indistinta los términos "cláusula arbitral" y "convenio arbitral". El legislador, nacional e internacional, decidió incluir ambos conceptos en la definición de qué se entiende por convenio arbitral y la doctrina ha terminado de perfilarlos. No es lo mismo una cláusula arbitral de corte genérico inserta en un contrato de otro tipo, que un contrato de arbitraje en el que se especifiquen todos los aspectos a tener en cuenta (ley aplicable al fondo, al convenio, al procedimiento, de la sede...). Hablar de uno u otro refleja aspectos muy distintos y su confusión pone de manifiesto el poco estudio que se ha realizado sobre el tema.

Segundo. La cuestión de la ley aplicable al convenio arbitral y al fondo es la gran asignatura pendiente del tribunal español. En el caso estudiado se dictamina que la ley aplicable para determinar la validez de la cláusula arbitral es la normativa eslovena. A pesar de ello, la AP insiste en aplicar la legislación española. Una vez que los instrumentos legales correspondientes han determinado una legislación extranjera como la ley aplicable, no interesa lo que tenga que decir la normativa estatal del tribunal para decidir el asunto. Si la ley aplicable contempla una solución o una vía distinta o no prevista en la contenida por la ley del tribunal que resuelve, no importa, no surge un conflicto de leyes. La ley aplicable es la ley extranjera y es a ella a la que hay que acudir para resolver. No hay dos leyes aplicables, sólo una. Sin embargo, este principio básico en DIPriv. parece difícil de asimilar por el tribunal, pues se muestra reacio a aplicar leyes que no sean las suyas. Todo lo que haya fuera de sus fronteras legislativas no existe. Esta insistencia por mantener todos los asuntos dentro del territorio nacional es peligrosa y arriesgada. Si un caso presenta elementos extranjeros, hay que acudir y aplicar las normas correspondientes para darle la mejor solución posible. Si se dictamina que un litigio tiene los vínculos más estrechos con otro Estado y, por tanto, es esa legislación la aplicable, forzar la situación y aplicar las normas españolas conlleva una situación de indefensión para las partes. Si la legislación aplicable es la eslovena, es ésta la ley que debe aplicarse. No se trata de resolver como lo haría un tribunal español, sino como lo haría un tribunal esloveno. De no hacerlo, la solución no será correcta, pues pueden existir elementos o figuras jurídicas que la ley española no permite pero la eslovena sí, y obviarlas pone de manifiesto una grave deficiencia en el fallo.

Tercero. Es deber del tribunal pronunciarse sobre todas aquellas cuestiones que han sido planteadas por las partes. La omisión de pronunciamiento o motivación de alguna cuestión podría conllevar la vulneración de la tutela judicial efectiva del art. 24 CE. Pero, aunque eso sea uno de los principios rectores del Derecho español, no es obstáculo para que la AP haga caso omiso a la alegación sobre la posible vulneración de la tutela judicial sufrida por una de las partes.

Cuarto. Aunque la resolución contenida en el fallo del auto haya sido acertada, esto no se debe al estudio de la normativa aplicable que la AP ha llevado a cabo. Se debe a que ambas leyes de arbitraje, española y eslovena en este caso, han tomado como modelo los convenios internacionales tratados en este comentario, dando lugar a un falso conflicto de leyes. Es decir, la aplicación de una u otra ley no conllevará resultados materialmente distintos, puesto que ambas se han basado en los mismos convenios para establecer su regulación. Se podría decir incluso que la buena resolución no es más que un hecho fortuito, pues de contener ambas leyes normas radicalmente distintas, la solución a la que habría llegado el tribunal también habría sido diferente. El tribunal parece tener miedo de aplicar cualquier ley extranjera y opta por constreñir el caso a la ley española, incluso cuando él mismo ha concluido que se trata de un supuesto con elementos internacionales. Esto pone de manifiesto el desconocimiento que se tiene del DIPriv., el cual se ve como algo lejano, borroso y problemático, pues supone aplicar leyes que no son las propias. En general, la argumentación realizada por la AP deja bastante que desear, ya que es incapaz de interpretar correctamente incluso la propia normativa española. 